\title{
Belief Rules vs. Decision Rules: A Preliminary Appraisal of the Problem
}

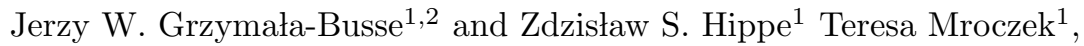 \\ 1 University of Information Technology and Management, \\ ul. Sucharskiego 2, 35-225 Rzeszw, Poland, \\ zhippe, tmroczek@wenus.wsiz.rzeszow.pl \\ 2 Department of Electrical Engineering and Computer Science, University of Kansas, \\ Lawrence KS 66045-7523, USA \\ jerzy@ku.edu
}

\begin{abstract}
An in-house developed computer program system BeliefSEEKER, capable to generate belief networks and to convert them into respective sets of belief rules, was applied in mining the melanoma database. The obtained belief rules were compared with production rules generated by LERS system. It was found, that belief rules can be presumably treated as a generalization of standard IF...THEN rules.
\end{abstract}

Keywords: belief networks, belief rules, production rules, Belief-

SEEKER, LERS

\section{Introduction}

In this research two distinct learning models were generated (using an in-house developed computer program system Belief SEEKER [1]), and then applied for classification of unseen cases of melanoma skin lesions. The first model was based on belief networks, whereas the second one was grounded on typical decision rules. The quality of the developed learning models was additionally compared with results gained by the program LERS [2], a well-known standard of rules generating systems.

\section{Research tools used}

- Belief SEEKER - is a computer program system, capable to generate learning models (for any type of decision table prepared in the format set about by Pawlak [3]) in a form of belief nets, applying various algorithms [4]. The development of belief networks is steadily controlled by a specific parameter, informing about the maximum dependence between variables, known as marginal likelihood:

$$
M L=\prod_{i=1}^{v} \prod_{j=1}^{q_{i}} \frac{\Gamma\left(\alpha_{i j}\right)}{\Gamma\left(\alpha_{i j}+n_{i j}\right)} \prod_{k=1}^{c_{i}} \frac{\Gamma\left(\alpha_{i j k}+n_{i j k}\right)}{\Gamma\left(\alpha_{i j k}\right)}
$$


Here:

$i=1, \ldots, v$ - where $\mathrm{v}$ is the number of nodes in the network,

$j=1, \ldots, q_{i}$ - is the number of possible combinations of parents of the node

$X_{i}$. (if a given attribute does not contain nodes of the type "parent", then $q_{i}$ get the value of 1 ),

$k=1, \ldots, c_{i}$ - where $c_{i}$ is the number of classes within the attribute $X_{i}$,

$n_{i j k}$ - is the number of rows in the database, for which parents of the at-

tribute $X_{i}$ have value $j$, and this attribute has the value of $k$, and

$\alpha_{i j k}, \alpha_{i j}$ - are parameters of the initial Dirichlet's [5] distribution.

Characteristic features of the system, yet not described by us are: (i) capability to generate various exhaustive learning models (Bayesian networks) for different values of Dirichlet's parameter [5], (ii) capability to convert generated belief networks into relevant sets of belief rules of the type IF...THEN, (iii) built-in classification mechanism of unseen cases, and (iv) built-in mechanism for the assessment of obtained rules. It is worth to mention, that developed learning models (belief nets) can be converted into some sets of belief rules, characterizes by a specific parameter called by us belief factor $\mathbf{B F}$, that reveals indirectly the influence of the most significant descriptive attributes on the dependent variable. Also, to facilitate the preliminary evaluation of generated rules, additional mechanism supports the calculation of their specifity, strength, generality, and accuracy [6].

- LERS[7] - data mining system (acronym from Learning from Examples based on Rough Sets), developed at the University of Kansas, Lawrence, $\mathrm{KS}$, USA, induces a set of rules from any kind of data (even from inconsistent data) and classifies new cases using the set of rules induced previously. These rules are more general than information contained in the original input database, since more new cases may be correctly classified by rules than may be matched with cases from the original data. More details about the system LERS can be find elsewhere [8].

\section{Experiments. Chosen results and discussion}

The well-known database [9] containing 548 cases of melanoma skin lesions was used in our research. It should be stressed that each case stored in the database was diagnosed, and confirmed histopathologically as belonging to one of the four concepts: Benign nevus, Blue nevus, Suspicious nevus, and Melanoma malignant. The database was randomly divided into two independent subsets. The first subset (E384144.TAB; 384 cases, 14 attributes, 4 concepts) was used for development of learning models, whereas the second (E164144.TAB; 164 cases, 14 attributes, 4 concepts) served for testing models. Information regarding the distribution of concepts in these sets is shown in Table 1.

In the first step of the research, computer program system Belief SEEKER was used to generate three different belief networks, having Dirichlet's para- 
Table 1. Distribution of investigated cases in learning and training sets

\begin{tabular}{|l|c|c|}
\hline Diagnosed concept & $\begin{array}{c}\text { E384144.tab } \\
\text { (learning set) }\end{array}$ & $\begin{array}{c}\text { E164144.tab } \\
\text { (testing set) }\end{array}$ \\
\hline \hline Benign nevus & 160 & 88 \\
\hline Blue nevus & 64 & 14 \\
\hline Suspicious nevus & 80 & 34 \\
\hline Melanoma malignant & 80 & 28 \\
\hline
\end{tabular}

meter $\alpha=1,30$ and 60 respectively. The basic difference in the structure of these networks relied on the number of the most distinctive (important) attributes, displaying direct influence on the dependent variable (type of skin lesion, the decision). It was found, for example, that for the network with $\alpha=1$ two descriptive attributes, namely $\langle T D S\rangle$ and $<$ color blue $>$ seemed to be the most important. Then, for networks with $\alpha=30$, additional attribute $(<$ asymmetry $\rangle$ ), appeared in the network. Finally, in the case of the third network, besides attributes pointed out earlier, the attribute $<$ dark brown $>$ was observed.

The significance of these attributed was of great importance. Based on this information - in the next step of the research - for variable values of $\mathbf{B F}$ parameter - various sets of rules were generated for each of the networks (for Belief SEEKER), and one, unique set of rules was generated by LERS (see Table 2 and Table 3 ). It was found that the best results were obtained for $\mathbf{B F}$ $=0.7$.

Table 2. The summary of results of classification of unseen cases by Belief SEEKER and LERS

\begin{tabular}{|l|c|c|c||c|}
\cline { 2 - 4 } \multicolumn{1}{l|}{} & \multicolumn{3}{|c|}{ Belief SEEKER } & \multirow{2}{*}{ LERS } \\
\cline { 2 - 4 } & Dirichlet's parameter & \\
\cline { 2 - 4 } & $\alpha=\mathbf{1}$ & $\alpha=\mathbf{3 0}$ & $\alpha=\mathbf{6 0}$ & \\
\hline \hline Number of rules & 20 & 31 & 42 & 49 \\
\hline $\begin{array}{l}\text { Number of cases } \\
\text { classified correctly } \\
{[\%]}\end{array}$ & 95.12 & 95.12 & 87.80 & 87.8 \\
\hline $\begin{array}{l}\text { Number of cases } \\
\text { classified incorrectly } \\
{[\%]}\end{array}$ & 4.88 & 4.27 & 4.88 & 6.10 \\
\hline $\begin{array}{l}\text { Number of cases } \\
\text { unclassified [\%] }\end{array}$ & 0 & 0.61 & 7.32 & 6.10 \\
\hline
\end{tabular}

In the last step of the research, selected information (like specificity, strength, generality and accuracy of generated rules) allowed to fix the strongest belief rules and decision rules (Table 4 ).

It can be assumed that, the increase of Dirichlet's parameter causes extending the most crucial belief rules (Table 4 ) by merging another attributes. It was also 
Table 3. Occurrences of selected attributes in belief rules (Belief SEEKER) and decision rules (LERS)

\begin{tabular}{|c|c|c|c|c|c|}
\hline \multirow{3}{*}{\multicolumn{2}{|c|}{ Descriptive attributes }} & \multirow{2}{*}{\multicolumn{3}{|c|}{\begin{tabular}{|c|} 
Belief SEEKER \\
Dirichlet's parameter
\end{tabular}}} & \multirow{4}{*}{\begin{tabular}{|c|} 
LERS \\
16
\end{tabular}} \\
\hline & & & & & \\
\hline & & \multirow[t]{2}{*}{$\alpha=\mathbf{1}$} & \multirow{2}{*}{$\begin{array}{c}\alpha=\mathbf{3 0} \\
31\end{array}$} & \multirow{2}{*}{$\frac{\alpha=\mathbf{6 0}}{42}$} & \\
\hline & asymmetry & & & & \\
\hline & border & & & & 25 \\
\hline \multirow{6}{*}{ Color } & black & & & & 11 \\
\hline & blue & 20 & 31 & 42 & 18 \\
\hline & dark brown & & & 42 & 5 \\
\hline & light brown & & & & 6 \\
\hline & red & & & & 16 \\
\hline & white & & & 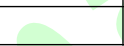 & 11 \\
\hline \multirow{6}{*}{$\begin{array}{c}\text { Diversity } \\
\text { of } \\
\text { structure }\end{array}$} & pigment dots & & & & 11 \\
\hline & pigment globules & & & & 6 \\
\hline & pigment network & & & 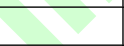 & 15 \\
\hline & structureless areas & & & 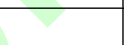 & 9 \\
\hline & branched streaks & & & & 9 \\
\hline & TDS & 20 & 30 & 42 & 33 \\
\hline
\end{tabular}

Table 4. Selected examples of the most important belief rules and decision rules

\begin{tabular}{|c|c|c|c|}
\hline \multicolumn{3}{|c|}{ Belief SEEKER } & \multirow{3}{*}{ LERS } \\
\hline \multicolumn{3}{|c|}{ Dirichlet's parameter } & \\
\hline$\alpha=1$ & $\alpha=\mathbf{3 0}$ & $\alpha=\mathbf{6 0}$ & \\
\hline $\begin{array}{l}\text { RULE } 5 \\
\text { IF TDS }>=4.080 \\
\text { AND TDS }<4.850 \\
\text { AND C_BLUE IS absent } \\
\text { THEN DIAGNOSIS IS } \\
\text { Benign_nev }\end{array}$ & $\begin{array}{l}\text { RULE } 3 \\
\text { IF TDS }>=4.080 \\
\text { AND TDS }<4.850 \\
\text { AND C_BLUE IS absent } \\
\text { AND ASYMMETRY IS } \\
\text { 1_axial_as } \\
\text { THEN DIAGNOSIS IS } \\
\text { Benign_nev }\end{array}$ & $\begin{array}{l}\text { RULE } 6 \\
\text { IF TDS }>=4.080 \\
\text { AND TDS }<4.850 \\
\text { AND C_BLUE IS absent } \\
\text { AND ASYMMETRY IS } \\
\text { 1_axial_as } \\
\text { AND C_d_BROWN IS } \\
\text { present } \\
\text { THEN DIAGNOSIS IS } \\
\text { Benign_nev }\end{array}$ & $\begin{array}{l}\text { RULE 1 } \\
\text { IF C_BLUE IS absent } \\
\text { AND C_d_BROWN IS } \\
\text { present } \\
\text { AND C_RED IS absent } \\
\text { AND D_PIGM_DOTS IS } \\
\text { present } \\
\text { AND ASYMMETRY IS } \\
\text { sym_change } \\
\text { THEN DIAGNOSIS IS } \\
\text { Benign_nev }\end{array}$ \\
\hline $\begin{array}{l}\text { RULE } 4 \\
\text { IF TDS }>=3.310 \\
\text { AND TDS }<4.080 \\
\text { AND C_BLUE IS absent } \\
\text { THEN DIAGNOSIS IS } \\
\text { Benign_nev }\end{array}$ & $\begin{array}{l}\text { RULE } 7 \\
\text { IF TDS }>=3.310 \\
\text { AND TDS }<4.080 \\
\text { AND C_BLUE IS absent } \\
\text { AND ASYMMETRY IS } \\
\text { sym_change } \\
\text { THEN DIAGNOSIS IS } \\
\text { Benign_nev }\end{array}$ & $\begin{array}{l}\text { RULE } 10 \\
\text { IF TDS }>=3.310 \\
\text { AND TDS }<4.080 \\
\text { AND C_BLUE IS absent } \\
\text { AND ASYMMETRY IS } \\
\text { sym_change } \\
\text { AND C_d_BROWN IS } \\
\text { present } \\
\text { THEN DIAGNOSIS IS } \\
\text { Benign_nev }\end{array}$ & $\begin{array}{l}\text { RULE 15 } \\
\text { IF C_BLUE IS absent } \\
\text { AND TDS }>=4.75 \\
\text { AND TDS }<5.35 \\
\text { AND C_WHITE IS present } \\
\text { AND C_BLACK IS absent } \\
\text { AND D_PIGM_NETW IS } \\
\text { absent } \\
\text { THEN DIAGNOSIS IS } \\
\text { Benign_nev }\end{array}$ \\
\hline $\begin{array}{l}\text { RULE } 19 \\
\text { IF TDS }>=4.850 \\
\text { AND TDS }<5.620 \\
\text { AND C_BLUE IS absent } \\
\text { THEN DIAGNOSIS IS } \\
\text { Suspicious }\end{array}$ & $\begin{array}{l}\text { RULE } 28 \\
\text { IF TDS }>4.850 \\
\text { AND TDS }<5.620 \\
\text { AND C_BLUE IS absent } \\
\text { AND ASYMMETRY IS } \\
\text { 1_axial_as } \\
\text { THEN DIAGNOSIS IS } \\
\text { Suspicious }\end{array}$ & $\begin{array}{l}\text { RULE } 39 \\
\text { IF TDS }>=4.850 \\
\text { AND TDS }<5.620 \\
\text { AND C_BLUE IS absent } \\
\text { AND ASYMMETRY IS } \\
1 \text { _axial_as } \\
\text { AND C_d_BROWN IS } \\
\text { present } \\
\text { THEN DIAGNOSIS IS } \\
\text { Suspicious }\end{array}$ & $\begin{array}{l}\text { RULE } 24 \\
\text { IF D_STREAKS IS absent } \\
\text { AND D_PIGM_DOTS IS } \\
\text { absent } \\
\text { AND C_BLUE IS present } \\
\text { THEN DIAGNOSIS IS } \\
\text { Blue_nevus }\end{array}$ \\
\hline
\end{tabular}


observed that strongest rules generated from the first network $(\alpha=1)$, became a base for rules generated from other networks ( $\alpha=30$ and 60).

The strongest decision rules generated by LERS system present more detailed study of cases, mainly because they contained greater number of descriptive attributes than respective belief rules, moreover, the attributes used were often completely different. Only the attribute <color blue $>$ was common for both sets of rules. Considering the overall results of classification (Table 2) the best results were obtained for belief networks with $\alpha=1$ or $\alpha=30$. Expanding the set of rules $(\alpha=60)$ with another attribute $-<$ color dark brown $>$ - did not improve the classification process. It may be pointed out, that generalizing of the rule sets yielded positive effects in term of classification process. Results of the carried out research has also showed that belief rules (produced by Belief SEEKER) seemed to be some kind of generalization of rules developed by LERS system. In the future research, the detailed foundation of this interesting finding will be dealt with.

\section{References}

1. P. Błajdo, J.W. Grzymała-Busse, Z.S. Hippe, M. Knap, T. Marek, T. Mroczek, M. Wrzesień: A suite of machine learning tools for knowledge extraction from data, In: R. Tadeusiewicz, A. Ligęza, M. Szymkat (Eds.), Computer Methods and Systems in Scientific Research, Edition of "Oprogr. Naukowe", Cracow 2003, pp. 479-484 (in Polish).

2. M.R. Chmielewski, J.W. Grzymała-Busse, Neil W. Peterson, S. Than: The Rule Induction System LERS - A Version for Personal Computers, Foundations of Computing and Dec. Sciences 1993 (18, No 3-4) pp. 181-211.

3. Z. Pawlak: Knowledge and rough set, In: W. Traczyk (Eds.), Problem of artificial intelligence, Wiedza i życie - Warsaw 1995, pp. 9-21 (in Polish).

4. T. Mroczek, J.W. Grzymała-Busse, Z.S. Hippe: Rules from belief networks: A Rough Set Approach, In: S. Tsumoto, R. Słowiński, J. Komorowski, J.W. Grzymała-Busse (Eds.), Rough Sets and Current Trends in Computing, SpringerVerlag, Uppsala, Sweden 2004, pp.483-487

5. D. Heckerman: A Tutorial on Learning Bayesian Networks, Technical report MSRTR-95-06. heckerman@microsoft.com.

6. Z.S. Hippe: Design and Application of New Knowledge Engineering Tool for Solving Real World Problems, Knowledge-Based Systems 9(1996)509-515.

7. J.W. Grzymała-Busse: A New Version of the Rule Induction System LERS, Fundamenta Informaticae 31(1997)27-39.

8. J.W. Grzymała-Busse, W. Ziarko: Data Using Based on Rough Sets, In: J.Wang (Eds.), Data Mining: Opportunities and Challenges, Idea Group Publishing, Hershey 2003, pp. 142-173.

9. A. Alvarez, S. Bajcar, F.M. Brown, J.W. Grzymała-Busse, Z.S. Hippe: Optimization of the ABCD Formula Used for Melanoma Diagnosis, In: M.A. Kłopotek, S.T. Wierzchoń, K. Trojanowski (Eds.), Advances in Soft Computing, Springer-Verlag, Heidelberg 2003, pp.233-240. 